\title{
Avaliação algimétrica e sinérgica em cães tratados pela levomepromazina, induzidos pelo tiopental e mantidos pelo sevofluorano, pré-tratados ou não pelo butorfanol
}

\section{Evaluation of analgesia and effects of butorphanol as premedicants in dogs anesthetized with levomepromazine/ thiopentone/ sevoflurane}

\author{
Rosana Maria de Oliveira Clark, ${ }^{*}$ Flávio Massone, ${ }^{* \star}$ Suzane Lílian Beier ${ }^{\star * *}$
}

\begin{abstract}
Resumo
Objetivou-se avaliar pela algimetria mecânica e térmica o sinergismo do butorfanol associado à levomepromazina em cães anestesiados pelo sevofluorano, induzidos pelo tiopental, avaliando-se os principais parâmetros fisiológicos, hemogasometria, BIS, recuperação e analgesia pós-anestésica. Aprovado pela comissão de ética da instituição, utilizaram-se 30 cães saudáveis, alocados em três grupos de 10 cada. Os animais de Gl receberam levomepromazina (0,5 mg/kg IV) na MPA, indução anestésica com tiopental (12,5 mg/kg IV) e manutenção pelo sevofluorano, durante 60 minutos. O mesmo protocolo foi realizado em Gll e GIII, porém associou-se o butorfanol (0,2 mg/kg IV) a levomepromazina, e em GIII a dose do tiopental foi aquela suficiente para abolir o reflexo laringotraqueal e realização da intubação orotraqueal. A dose média do tiopental em GIII foi $7,05 \mathrm{mg} / \mathrm{kg}$. Não foi observada taquicardia após intubação em Gll e Glll, enquanto que durante manutenção anestésica, a freqüência cardíaca apresentou valores inferiores a Gl e a pressão arterial manteve-se mais estável, apesar da moderada

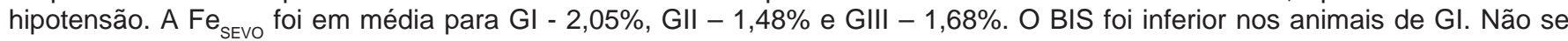
notaram alterações significativas nas variáveis respiratórias, hemogasométricas e recuperação anestésica. A resposta ao estímulo mecânico e térmico foi superior nos grupos tratados pelo butorfanol (Gll - 74min e 49min; GllI - 59min e 42min). Concluiu-se que o butorfanol determinou estabilidade hemodinâmica e respiratória no protocolo utilizado, e que apesar de diminuir o componente hipnótico revelado pelo BIS, melhorou a qualidade da anestesia, reduzindo o consumo de tiopental e sevofluorano, proporcionando analgesia na recuperação anestésica, não influenciando na mesma.
\end{abstract}

Palavras-chave: sevofluorano, butorfanol;,índice bispectral (BIS), algimetria, cães.

\begin{abstract}
The aim of this study was to evaluate the synergism of butorphanol by thermal and mechanical stimulus, by evaluation of cardiovascular, respiratory and hemogasometric parameters, bispectral index (BIS), recovery time and post-anesthetic analgesia. After approved for the Institution Animal Ethics Commission, thirty dogs considered healthy, were allocated in three groups of 10 each. The animals in GI were premedicated with levomepromazine $(0,5 \mathrm{mg} / \mathrm{kg})$, induced by thiopental $(12,5 \mathrm{mg} / \mathrm{kg})$ and anesthesia was maintained with sevoflurane during $60 \mathrm{~min}$. The same protocol was accomplished in Gll and Glll with butorphanol (0,2 mg/ $\mathrm{kg}$ ) associated to levomepromazine, and in GIll the dose of thiopental was sufficient to abolish protector reflex and ensure endotracheal intubation. The dose induction of thiopental in GIII was $7,04 \mathrm{mg} / \mathrm{kg}$. Tachycardia was not observed after intubation in GII and GIII, while during anesthetic maintenance the heart rate were inferior than GI, and in spite of hypotension, the blood

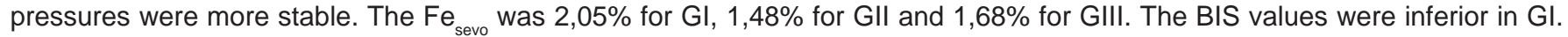
There were no significative differences among respiratory, hemogasometric and recovery parameters. Time to response interdigital mechanical and thermal nociceptive stimulus, were longer in animal treated with butorphanol (GII - 74min. and 49min.; GIII $59 \mathrm{~min}$. and $42 \mathrm{~min}$.). It is concluded that, butorphanol provides cardiovascular, respiratory and hemogasometric stability, with adequate analgesia in post-anesthetic period. In spite of reduce hypnotic component revealed by the BIS, it improved the quality of anesthesia, by decreasing thiopental and sevoflurane consumption, providing analgesia in the anesthetic recovery, no influence the same.
\end{abstract}

Keywords: sevoflurane; butorphanol; bispectral index (BIS); algimetry; dogs.

\footnotetext{
* Doutora em Anestesiologia Veterinária pela FMVZ-UNESP-Campus de Botucatu - SP, Brasil - e-mail: roclark@ig.com.br

** Professor titular do Departamento de Cirurgia e Anestesiologia Veterinária - FMVZ - Unesp - Botucatu - SP, btflama@uol.com.br

${ }^{* * *}$ Doutoranda em Anestesiologia Veterinária - Faculdade de Medicina de Botucatu - Unesp - Botucatu - SP.
} 


\section{Introdução}

Em anestesiologia veterinária, é grande a preocupação em se chegar a um protocolo anestésico ideal visando-se maior segurança para o paciente, e conseqüentemente melhor qualidade anestésica. Nos últimos anos, a necessidade de tratamento da dor pós-operatória vem ganhando destaque, uma vez que a dor aguda contribui para a ocorrência de diversas complicações pós-operatórias, aumentando a resposta de estresse, prolongando a recuperação, bem como elevação da morbidade. A utilização de opióides como componente de uma anestesia balanceada oferece diversas vantagens: além do sinergismo entre os fármacos utilizados, minimizando as flutuações na dinâmica cardiovascular, proporciona analgesia no decurso da anestesia e pós-operatório (Murphy e Hug, 1882; Waterman e Amin, 1991; Cornick e Hartsfield, 1992; Ko Jef et al., 2000). Por outro lado, os agentes opióides apresentam o inconveniente de promover depressão respiratória dose-dependente (Fantoni e Cortopassi, 2002). O butorfanol é um opióide sintético de ação agonista nos receptores $\mathrm{k}$ e antagonista em m (Vandan, 1981). Em virtude de sua mínima depressão no sistema respiratório (Schurig et al., 1978; Trim, 1983), este agente se torna adequado para ser utilizado em associações anestésicas. Além disso, o butorfanol possui uma característica conhecida como "efeito teto", significando que doses adicionais ou maiores deste agente não aumentariam a depressão respiratória (Murphy e Hug, 1981). A dose empregada varia de 0,05 a $0,2 \mathrm{mg} / \mathrm{kg}$ pela via intravenosa (IV). Sua duração de ação é descrita como de quatro hora; entretanto, seu efeito analgésico parece não perdurar mais que duas horas (Fantoni e Cortopassi, 2002). Sobre a atividade cardiovascular, o butorfanol pode determinar redução da freqüência cardíaca, pressão arterial sangüínea e débito cardíaco (Muldoon et al., 1983; Trim, 1983). Da mesma forma, quando associado a acepromazina, reduz significativamente a freqüência cardíaca (Cornick e Hartsfield, 1992; Otero et al., 2000). Greene et al. (1990) observaram durante os primeiros 15 minutos de manutenção anestésica pelo halotano em cães, que o butorfanol reduziu a freqüência cardíaca e a pressão arterial sangüínea. Entretanto, com recuperação dos valores basais aos 30 minutos, manteve-se estável até o término da anestesia. Tem-se observado uma depressão cardiovascular moderada durante a anestesia pelo isofluorano em cães que receberam butorfanol na dose de $0,2 \mathrm{mg} / \mathrm{kg}$ IV (Tyner et al., 1989). Por outro lado, Mutoh et al. (2002) observaram estabilidade da freqüência cardíaca durante indução por máscara com sevofluorano em cães que receberam a associação de acepromazina/butorfanol; entretanto, esses animais apresentaram redução acentuada e gradativa da PAM até o momento da intubação endotraqueal.

O sevofluorano, agente anestésico inalatório mais recentemente introduzido na prática clínica, possui coeficiente de solubilidade sangue/gás baixo $(0,6 \pm 0,07)$, o que permite indução e recuperação extremamente rápidas e suaves, permitindo ainda fácil controle da profundidade anestésica. Além disso, possui odor agradável e não pungente, o que permite indução anestésica via máscara facial (Smith et al., 1996). Por essas razões, sua utilização se torna bastante atraente em medicina veterinária e vem ganhando espaço com futuro promissor. $\mathrm{Na}$ espécie canina, ao contrário do que ocorre no homem, a freqüência cardíaca mantém valores mais elevados, podendo esta resposta ser causada por uma menor depressão sobre a resposta barorreflexa induzida (Mutoh et al., 1997; Oliva et al.,
2000). A redução da pressão arterial é proporcional ao aumento da concentração de sevofluorano administrado. Entretanto, devido ao seu baixo coeficiente de solubilidade sangue/gás e à fácil interferência no plano anestésico, ocorre um melhor controle hemodinâmico quando comparado aos outros agentes halogenados (Kazama e Ikeda, 1985).

O Índice Bispectral (BIS), valor derivado do eletroencefalograma, tem mostrado ser medida quantificável dos efeitos sedativos e hipnóticos de fármacos anestésicos sobre o sistema nervoso central (Rosow e Manberg, 1998; Vianna, 2001), sendo bom indicador da profundidade anestésica (Glass et al., 1997). O BIS é obtido através de recepção de sinais captados por eletrodos posicionados nas regiões frontais e temporal esquerda ou direita do paciente. No painel frontal do monitor, é fornecida a leitura direta e contínua do BIS em escala de 100 a zero. Quando a escala do BIS se apresenta próxima do valor de 100, o paciente encontra-se acordado, ou seja, não sofreu influência de qualquer fármaco hipnótico. À medida que se infunde um fármaco hipnótico, a escala do BIS vai reduzindo proporcionalmente os níveis de sedação e hipnose, sendo 70 considerado como sedação leve, abaixo de 60 níveis profundos de hipnose e 0 (zero) representando traçado isoelétrico de supressão da atividade cerebral (Vianna, 2001).

A avaliação da dor nos animais é subjetiva e varia de acordo com o observador. A algimetria mecânica e térmica são técnicas desenvolvidas para avaliação da dor e permitem quantificar através de estímulo nociceptivo a eficácia dos agentes analgésicos. Rosa (2001), utilizando a associação de levomepromazina/ midazolam/ quetamina/ butorfanol, observou um período de analgesia de três horas, através da avaliação algimétrica pelos métodos mecânico e térmico. Waterman e Amin (1991), aplicando a técnica desenvolvida por Nolan et al. (1987), que permite quantificar a eficácia dos agentes analgésicos frente a um estímulo nociceptivo térmico e mecânico, observaram que em ovelhas o butorfanol $(0,2 \mathrm{mg} / \mathrm{kg})$ foi bastante eficaz em controlar a dor provocada por estímulo térmico por um período de 120 a 130 minutos, numa temperatura média de $60^{\circ} \mathrm{C}$. Por outro lado, os autores não constataram aumento da força mecânica nas três doses utilizadas de butorfanol $(0,05 ; 0,1$ e $0,2 \mathrm{mg} / \mathrm{kg})$, sendo este opióide ineficaz em suprimir a dor provocada por estímulo nociceptivo mecânico neste modelo de dor em ovelhas.

Contudo, a presente pesquisa teve como objetivo avaliar, através da algimetria térmica e mecânica, o sinergismo da associação levomepromazina, tiopental e sevofluorano com o prétratamento ou não pelo butorfanol, observando-se a interferência no consumo do sevofluorano, a redução da dose de tiopental, além da analgesia proporcionada por este opióide no período pós-anestésico.

\section{Material e método}

Após a aprovação pelo Comitê de Ética na Experimentação Animal da FMB-UNESP-Campus de Botucatu, foram utilizados 30 cães adultos, sem raça definida, sendo 22 fêmeas e oito machos, provindos do Biotério Central. Os animais foram distribuídos aleatoriamente em três grupos de 10 cada, sendo submetidos a jejum alimentar de 12 horas e hídrico de duas horas, na véspera do experimento. O grupo I (GI) recebeu na medicação pré-anestésica (MPA) a levomepromazina ${ }^{1}$ $(0,5 \mathrm{mg} / \mathrm{kg})$ pela via intravenosa (IV) e decorridos 15 minutos 
o tiopental sódico² (12,5 mg/kg IV) como agente indutor. A manutenção anestésica foi efetuada pelo sevofluorano ${ }^{3} \mathrm{com}$ fluxo diluente de 0,5 a 1,0 litro/min em $100 \%$ de oxigênio, em circuito circular semifechado. Nos animais do grupo II e III (GII e GIII), foi associado à levomepromazina o butorfanol ${ }^{4}(0,2$ $\mathrm{mg} / \mathrm{kg}$ IV), sendo que em GIII a dose de aplicação do tiopental foi suficiente para abolir o reflexo laringotraqueal para posterior realização da intubação orotraqueal. Após a indução anestésica, os animais eram posicionados sobre colchonete térmico na calha da mesa experimental onde se iniciava a manutenção anestésica que perdurou por 60 minutos para ambos os grupos. Foi conectado entre a sonda e o " $Y$ " do aparelho de anestesia, ${ }^{5}$ um analisador de gases ${ }^{6}$ para a monitoração contínua da concentração inspirada e expirada de sevofluorano $\left(\mathrm{Fi}_{\mathrm{SEV}} \mathrm{Fe}_{\mathrm{SEVO}}\right)$, assim como a freqüência respiratória $(f)$, volume corrente $\left(\mathrm{V}_{\mathrm{T}}\right)$, volume minuto $\left(\mathrm{V}_{\mathrm{M}}\right)$, concentração de dióxido de carbono no final da expiração $\left(\mathrm{ETCO}_{2}\right)$ e as frações inspirada e expirada de oxigênio $\left(\mathrm{FiO}_{2}, \mathrm{FeO}_{2}\right)$. Também foram avaliadas a temperatura corpórea, a saturação periférica de oxigênio na hemoglobina $\left(\mathrm{SatO}_{2}\right)$, freqüência cardíaca (FC) e pressão arterial média (PAM), pelos métodos não-invasivos (ninv) através da mensuração por manguito inflável cuja largura era de $40 \%$ do perímetro na área mensurada, avaliada pelo mesmo aparelho da pressão invasiva (inv). ${ }^{7} \mathrm{O}$ valor derivado do $\mathrm{BIS}^{8}$ foi obtido através da colocação de dois eletrodos frontais e um temporal, fazendose a leitura direta em todos os momentos (M0 a M9) no monitor do aparelho de eletroencefalograma microprocessado (Figura 1), sendo o resultado numérico avaliado através da escala

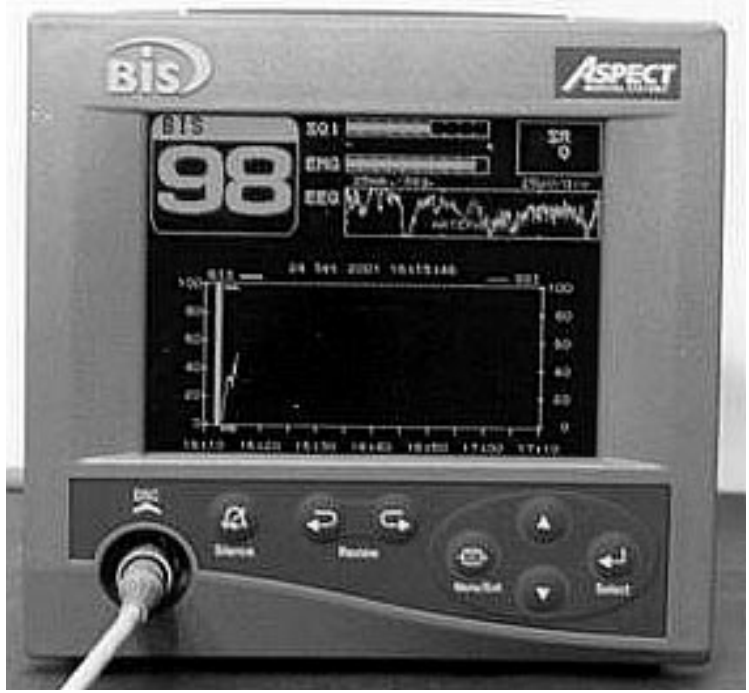

Figura 1 - Aparelho de análise do índice bispectral - BIS

\footnotetext{
Neozine - Rhodia Farma - São Paulo, SP.

Tiopental - Cristália Produtos Químicos e Farrmacéuticos.

Sevorane - Abbott Laboratórios do Brasil Ltda.

Torbugesic - Fort Dodge, Saúde Animal Ltda.

5 Aparelho de Anestesia Galant - Conquest 3000, Slim Conjunto Conquest - HB HOSPITALAR.

6 Capnomac Ultima - Monitor de Gases - Datex Engstrom

PC SCOUT/Multigas Analyser - SPACE LABS MEDICAL - Redmond - USA.

8 Bispectral Index - BIS Monitor A-2000. Aspect Medical System, Inc. Brasil
}

do BIS representada na Tabela 1. A análise hemogosométrica ${ }^{9}$ foi realizada durante a manutenção anestésica após colheita de amostras de sangue arterial através do cateter fixado na artéria femoral, sendo avaliados o $\mathrm{pH}$, a $\mathrm{PaCO}_{2}, \mathrm{PaO}_{2}$ e bicarbonato $\left(\mathrm{HCO}_{3}^{-}\right)$.

A algimetria mecânica foi avaliada através de um pressoalgímetro, ${ }^{10}$ cuja pressão foi aplicada na membrana interdigital dos membros anteriores e posteriores do animal (Figura 2), registrando-se o valor em $\mathrm{kgf} / \mathrm{cm}^{2}$ no momento da retirada do membro, sendo o resultado final calculado em média. Da mesma forma, a algimetria térmica, ${ }^{11}$ que foi avaliada por um termoalgímetro, onde se aplicava um bastão aquecido a uma temperatura fixa de $52^{\circ} \mathrm{C}$, contando-se em segundos o quanto o animal suportava até retirada do membro ( $\mathrm{Fi}$ gura 3). Em ambas as aferições não se ultrapassaram 5 segundos de mensuração para se evitar desconforto ou lesão tissular. No período pós-anestésico essas mensurações foram realizadas até a recuperação do valor basal, avaliandose, assim, a analgesia pelo butorfanol neste período. Após a desconexão da sonda do aparelho de anestesia inalatória foram registrados os períodos de tempo para extubação orotraqueal, alcance da posição esternal e finalmente a posição quadrupedal, bem como a recuperação da consciência registrada através do BIS.

Os momentos avaliados foram MO - imediatamente antes da MPA, M1 - 15 minutos após M0 e imediatamente antes da indução anestésica, M2 - 5 minutos após a indução anestésica, M3 a M8 - a cada 10 minutos durante a manutenção anestésica e M9 - 10 minutos após a interrupção da volatização do sevofluorano.

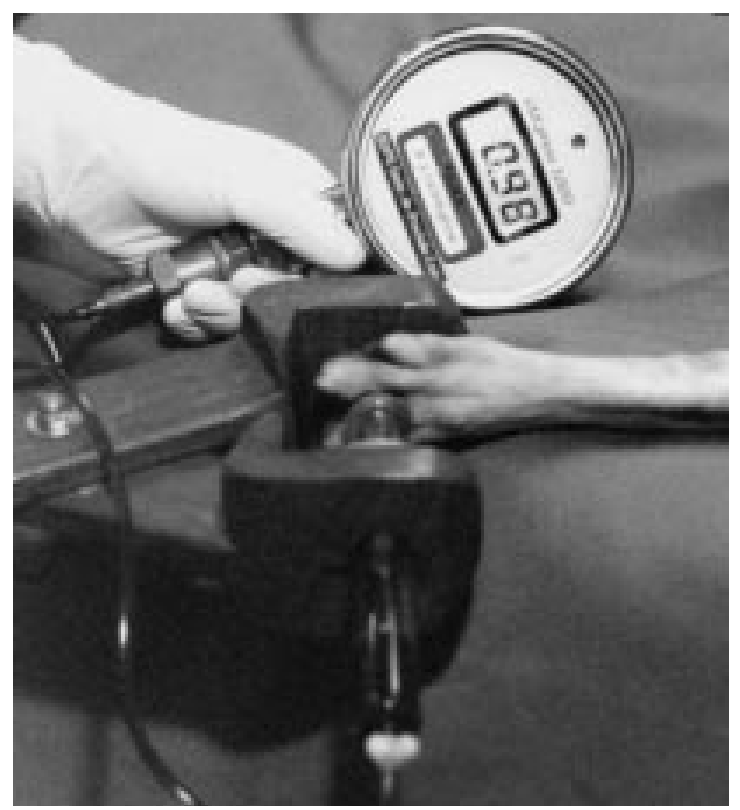

Figura 2 - Estimulação mecânica através da pressão da membrana interdigital em membro anterior de cão, com o pressoalgímetro.

\footnotetext{
9 248pH/Blood Gas Analyser - CHIRON/Diagnostics

10 Pressoalgímetro IOPE Instrumentos de precisão Ltda. Brasil

11 Termoalgímetro - IOPE Instrumentos de precisão Ltda.
} 
Tabela 2 - Valores medianos, $1^{\circ}$ e $3^{\circ}$ quartis das variáveis cardiovasculares, da temperatura retal (TR) e oximetria de pulso $\left(\mathrm{SatO}_{2}\right)$ em cães anestesiados pelo sevofluorano, pré-tratados com levomepromazina, induzidos com tiopental sódico na dose de $12,5 \mathrm{mg} / \mathrm{kg}(\mathrm{Gl})$ ou submetidos ao mesmo tratamento e tratados pelo butorfanol (Gll) ou com doses menores de tiopental e tratados com butorfanol (GIII) em diferentes momentos (M).

\begin{tabular}{|c|c|c|c|c|c|c|c|c|c|c|c|}
\hline & Momentos & MO & $\overline{M 1}$ & M2 & M3 & M4 & M5 & M6 & M7 & M8 & M9 \\
\hline Variáveis & & & & & & & & & & & \\
\hline \multirow{6}{*}{$\begin{array}{c}\text { FC } \\
\text { (bpm) }\end{array}$} & GI & $104,0^{\mathrm{B}}$ & $102,0^{\mathrm{Ba}}$ & $149,0^{\mathrm{A}}$ & $119,0^{\mathrm{Ba}}$ & $111,0^{\mathrm{Ba}}$ & $110,0^{\mathrm{Ba}}$ & $112^{, 0 \mathrm{Ba}}$ & $116,0^{\mathrm{Ba}}$ & $115^{, 0 \mathrm{Ba}}$ & $132,0^{\mathrm{Ba}}$ \\
\hline & $1^{\circ}-3^{\circ}$ quartis & $96-124$ & $95-113$ & $125-158$ & $110-136$ & $98-130$ & $92-127$ & $93-133$ & $100-125$ & $102-125$ & $117-137$ \\
\hline & Gil'" & $110,0^{A}$ & " 83,0 ' & $100,0^{3}$ & 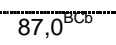 & 88,0 & 81,0 & 84,0 & 82,0 & "83,0 & "84,0 \\
\hline & $1^{\circ}-3^{\circ}$ quartis & $100-132$ & $72-112$ & $77-125$ & $78-107$ & $67-93$ & $67-93$ & $65-87$ & $66-91$ & $77-92$ & $75-124$ \\
\hline & Gilil & 99,0 & $80,0^{\circ}$ & 88,0 & $81,0^{\mathrm{b}}$ & $82,0^{6}$ & $84,0^{6}$ & $80,0^{6}$ & $77,0^{6}$ & $83,0^{6}$ & $87,0^{6}$ \\
\hline & $1^{O}-3^{O}$ quartis & $85-105$ & $71-91$ & $83-100$ & $72-98$ & $70-105$ & $58-105$ & $68-103$ & $59-98$ & $60-95$ & $75-95$ \\
\hline \multirow{6}{*}{$\begin{array}{c}\text { PAM } \\
\text { ninv } \\
(\mathrm{mmHg})\end{array}$} & GI & $78,5^{\mathrm{Bc}}$ & $75,0^{\mathrm{C}}$ & $66,5^{\mathrm{D}}$ & $60,0^{\mathrm{E}}$ & $55,5^{\mathrm{E}}$ & $55,5^{\mathrm{E}}$ & $63,5^{\mathrm{E}}$ & $68,0^{\mathrm{D}}$ & $77,0^{\mathrm{B}}$ & $92,5^{A}$ \\
\hline & $1^{O}-3^{O}$ quartis & $73-91$ & $71-87$ & $59-78$ & $55-67$ & $50-68$ & $53-64$ & $60-65$ & $61-79$ & $68-86$ & $81-108$ \\
\hline & Gil "' & $89,0^{215}$ & $78,5^{\mathrm{B}}$ & 56,5 & 64,5 & 57,0 & 52,5 & 53,5 & 55,0 & 61,5 & $84,0^{\mathrm{A}}$ \\
\hline & $1^{\circ}-3^{\circ}$ quartis & $80-103$ & $69-83$ & $51-79$ & $44-75$ & $51-60$ & $46-60$ & $49-64$ & $43-74$ & $46-70$ & $75-102$ \\
\hline & Gill'"' & 98,0 & 76,5 & 68,0 & $60,0^{\text {VEE }}$ & 56,0 & 60,0 & 66,0 & 75,0 & 64,0 & $86,0^{B}$ \\
\hline & $1^{\circ}-3^{\circ}$ quartis & $95-125$ & $72-91$ & $59-73$ & $54-67$ & $46-73$ & $50-70$ & $55-84$ & $57-85$ & $52-76$ & $75-120$ \\
\hline \multirow{6}{*}{$\begin{array}{c}\text { PAM } \\
\text { inv } \\
(\mathrm{mmHg})\end{array}$} & GI & & & $74,5^{\mathrm{D}}$ & $69,0^{\mathrm{E}}$ & $69,4^{\mathrm{E}}$ & $68,0^{\mathrm{E}}$ & $77,5^{\mathrm{Da}}$ & $82,0^{\mathrm{Ca}}$ & $92,5^{\mathrm{Ba}}$ & $106,0^{A}$ \\
\hline & $1^{\circ}-3^{\circ}$ quartis & & & $67-84$ & $57-75$ & $61-77$ & $63-76$ & $72-83$ & $73-94$ & $80-99$ & $97-113$ \\
\hline & Gill & & & $62,5^{\mathrm{BC}}$ & $63,5^{\mathrm{BC}}$ & $63,0^{\mathrm{C}}$ & $65,0^{B C^{-\cdots}}$ & $65,0^{\mathrm{BCD}}$ & $68,5^{\mathrm{BCD}}$ & $72,5^{\mathrm{Bb}}$ & $87,5^{\mathrm{A} \cdots}$ \\
\hline & $1^{\circ}-3^{\circ}$ quartis & & & $58-72$ & $58-71$ & $55-67$ & $62-66$ & $62-68$ & $64-71$ & $66-75$ & $79-91$ \\
\hline & Gill' & & & $77,0^{B}$ & $67,0^{B}$ & $65,0^{B}$ & 63,0 & $63,5^{\mathrm{Bb}}$ & $69,0^{85}$ & $70,0^{B b^{\prime}}$ & $94,5^{\mathrm{A}}$ \\
\hline & $1^{\circ}-3^{\circ}$ quartis & & & $62-83$ & $64-71$ & $63-69$ & $60-66$ & $62-70$ & $63-72$ & $63-79$ & $86-110$ \\
\hline \multirow{6}{*}{$\begin{array}{c}\text { TR } \\
\left(\mathrm{T}^{\circ} \mathrm{C}\right)\end{array}$} & GI & $39,5^{\mathrm{A}}$ & $38,8^{B}$ & $38,2^{\mathrm{Ca}}$ & $38,0^{\mathrm{Da}}$ & $37,8^{\mathrm{Ea}}$ & $37,7^{\mathrm{Ea}}$ & $37,7^{\mathrm{Ea}}$ & $37,7^{\mathrm{Ea}}$ & $37,7^{\text {Ea }}$ & $37,7^{\mathrm{Ea}}$ \\
\hline & $1^{\circ}-3^{\circ}$ quartis & $39,2-39,7$ & $38,8-39,2$ & $38,0-38,3$ & $37,8-38,0$ & $37,6-37,9$ & $37,5-37,9$ & $37,4-37,9$ & $37,4-38,0$ & $37,4-38,0$ & $37,5-38,0$ \\
\hline & GIII' & $39,4^{A}$ & $39,0^{8}$ & 38,0 & 37,8 & 37,4 & $37,2^{-F^{\prime}}$ & 36,8 & 36,6 & $36,4^{100}$ & $36,2^{38^{\prime}}$ \\
\hline & $1^{\circ}-3^{\circ}$ quartis & $39,3-39,5$ & $38,5-39,2$ & $37,7-38,5$ & $37,2-38,4$ & $37,1-38,2$ & $36,8-38,0$ & $36,5-37,9$ & $36,3-37,9$ & $36,1-37,8$ & $36,0-37,8$ \\
\hline & "Gili' & $39,0^{\mathrm{A}-\cdots}$ & $38,3^{B}$ & $37,4^{\mathrm{cb}}$ & $37,2^{\square \sigma}$ & $37,0^{\mathrm{EC}}$ & 36,8 & $36,5^{\mathrm{GC}}$ & $36,3^{416}$ & $36,2^{16}$ & $36,2^{36^{\prime}}$ \\
\hline & $1^{\circ}-3^{O}$ quartis & $38,9-39,3$ & $38,0-39,0$ & $37,2-37,9$ & $37,0-37,7$ & $36,8-37,4$ & $36,6-37,2$ & $36,4-37,0$ & $36,0-36,6$ & $35,9-36,5$ & $35,8-36,4$ \\
\hline \multirow{6}{*}{$\begin{array}{c}\text { SatO }_{2} \\
(\%)\end{array}$} & GI & $98,5^{(1,2)}$ & 98,0 & 99,0 & 99,0 & 99,0 & 99,0 & 99,0 & 99,0 & 99,0 & 97,0 \\
\hline & $1^{\circ}-3^{\circ}$ quartis & $97-99$ & $97-99$ & $99,0-99$ & $99-99$ & $98-99$ & $98-99$ & $98-99$ & $98-100$ & $98-100$ & $96-98$ \\
\hline & Gil & $97,5^{(7,2)}$ & 97,5 & 99,0 & 99,0 & 99,0 & 99,0 & 99,0 & 99,0 & 99,0 & 97,0 \\
\hline & $1^{\circ}-3^{\circ}$ quartis & $96-99$ & $96-99$ & $99-100$ & $99-99$ & $99-99$ & $99-99$ & $99-99$ & $99-99$ & $99-100$ & $97-97$ \\
\hline & GIII & $97,0^{\mathrm{D}(2)}$ & $97,0^{C}$ & $99,0^{\mathrm{A}}$ & $99,0^{\mathrm{A}}$ & $99,0^{\mathrm{A}}$ & $99,0^{\mathrm{A}}$ & $99,0^{\mathrm{A}}$ & $99,0^{\mathrm{A}}$ & $99,0^{\mathrm{A}}$ & $98,0^{\mathrm{B}}$ \\
\hline & $1^{\circ}-3^{\circ}$ quartis & $96-98$ & $96-97$ & $99-99$ & $99-99$ & $99-99$ & $99-99$ & $99-100$ & $99-100$ & $99-100$ & $97-99$ \\
\hline
\end{tabular}

Letras maiúsculas diferentes indicam diferenças significativas $(p<0,05)$ entre momentos para cada grupo.

Letras minúsculas diferentes indicam diferenças significativas $(p<0,05)$ entre grupos para cada momento.

(1) Não houve diferença estatisticamente significativa na comparação dos momentos dentro do grupo.

(2) Não foram verificadas diferenças significativas $(p>0,05)$ entre grupos para cada momento.

= não foram feitas avaliações nestes momentos. 


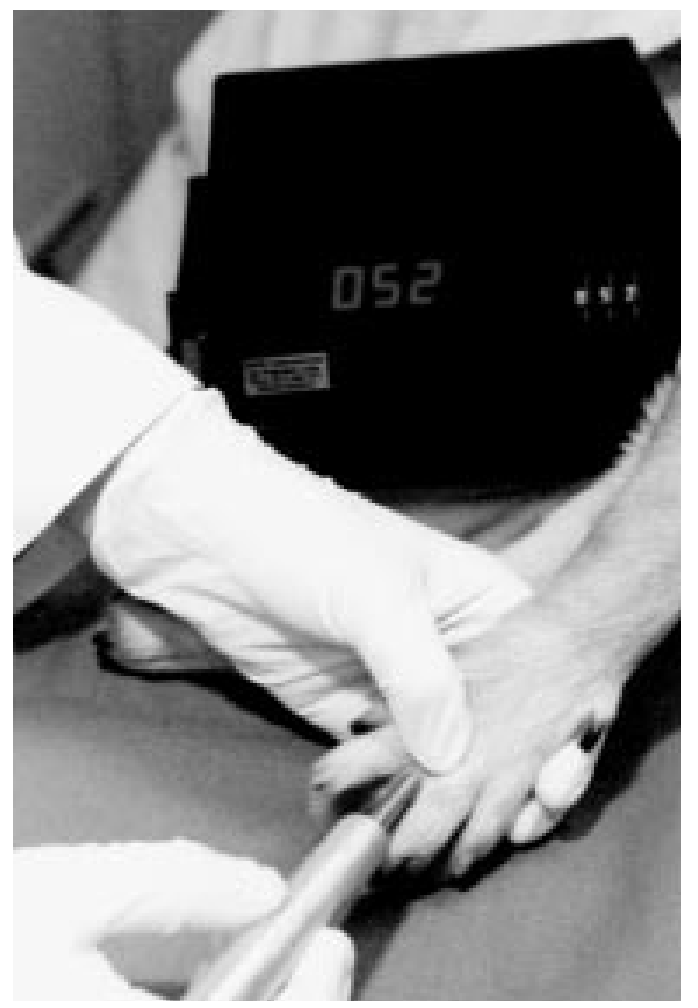

Figura 3 - Avaliação térmica na membrana interdigital do membro anterior do cão, através do termoalgímetro, a $52^{\circ} \mathrm{C}$.

A análise estatística foi realizada através dos testes nãoparamétricos de Friedman para comparação de momentos em cada grupo e o de Kruskal-Wallis para comparação dos grupos em cada momento, seguidos dos métodos de comparações múltiplas. Os resultados foram apresentados pelos valores medianos, 1ㅇ e 3 quartis. Para as variáveis que apresentaram distribuição normal e homogeneidade de variâncias foi utilizada análise de variância paramétrica, seguida do método de Tukey para comparações múltiplas, sendo os resultados apresentados por médias e desvio-padrão. O nível de significância utilizado foi de $5 \%$. Foi realizada ainda a correlação pelo coeficiente de Pearson entre os métodos de avaliação das pressões arteriais pelos métodos invasivo e não-invasivo.

\section{Resultados}

A dose média requerida de tiopental sódico para indução anestésica nos animais de Glll foi de $7,0 \mathrm{mg} / \mathrm{kg}$.

Os resultados das avaliações dos atributos nos momentos estudados estão descritos nas Tabelas 2, 3, 4 e 5, respectivamente. Os três grupos de estudo se comportaram de maneira bastante similar com relação à $\mathrm{SatO}_{2,}, \mathrm{~V}_{\mathrm{T}}, \mathrm{V}_{\mathrm{M}}, \mathrm{FiO}_{2}$, $\mathrm{FeO}_{2}$, e hemogasometria $\left(\mathrm{pH}, \mathrm{PaCO}_{2}, \mathrm{PaO}_{2}, \mathrm{HCO}_{3}^{-}\right)$, não resultando em diferenças significativas entre os grupos ( $\mathrm{Ta}$ belas 2, 3, 4 e 5).

Quanto a FC, foi observada em Gl elevação significativa após indução anestésica (M2) com tiopental, sendo que em Gll esta elevação não foi tão acentuada e em GIII, este parâmetro manteve-se estável em todos os momentos (figura 4). Durante a manutenção pelo sevofluorano, os valores da FC em Gl foram mais elevados quando comparados a Gll e GIII (Tabela 2).

Nos animais de Gl a PAMninv demonstrou hipotensão progressiva até M2. Durante a manutenção pelo sevofluorano apesar da hipotensão observada, os animais de Gll e GIII apresentaram estabilidade até o fim da anestesia inalatória, quando comparada aos animais de Gl que apresentaram elevação significativa da PAM em M6, M7, M8 (Tabela 2). A correlação obtida entre os métodos de avaliação das pressões arteriais sangüínea encontra-se no Quadro 1.

A temperatura retal no decorrer do experimento mostrou que em todos os grupos houve discreta hipotermia, apesar do emprego do colchão térmico, fato este mais acentuado em G II e G III, grupos que receberam o butorfanol.

$\mathrm{A} \mathrm{ET}_{\mathrm{CO} 2}$ apresentou valores superiores em M2 de Gl em relação a Gll e GIII. Entretanto, este parâmetro se manteve estável e sem alterações significativas entre os grupos nos outros momentos estudados. Apesar da avaliação estatística demonstrar valores inferiores do BIS, tal alteração não foi biologicamente digna, de nota pois houve uma tendência ao retorno a valores basais (Figura 5).

$\mathrm{Na}$ Figura 6 está representado o resultado referente ao período de recuperação anestésica, assim como o período de analgesia avaliado pelos métodos algimétricos, mecânico e térmico, bem como a recuperação da consciência avaliada pelo BIS.

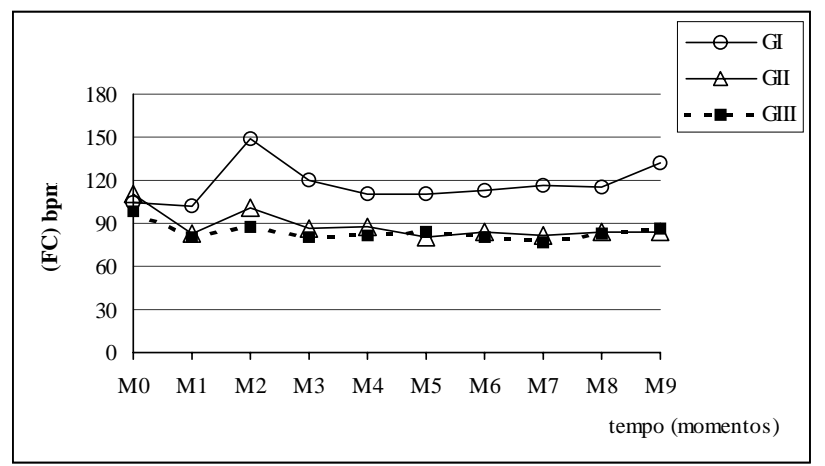

Figura 4 - Variação dos valores medianos da FC (bpm), em cães anestesiados pelo sevofluorano, pré-tratados com levomepromazina, induzidos com tiopental sódico na dose de $12,5 \mathrm{mg} / \mathrm{kg}$ (GI) ou submetidos ao mesmo tratamento e tratados pelo butorfanol (GII) ou com doses menores de tiopental e tratados com butorfanol (GIII) em diferentes momentos. ${ }^{*}$ indica diferença estatística entre grupos para cada momento; " indica diferença entre momentos para cada grupo $(p<0,05)$.

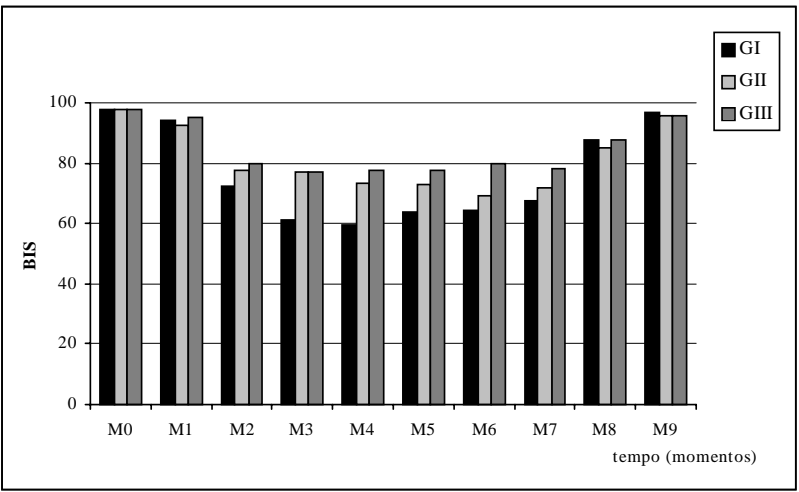

Figura 5 - Mediana dos valores de BIS em cães anestesiados pelo sevofluorano, pré-tratados com levomepromazina, induzidos com tiopental sódico na dose de $12,5 \mathrm{mg} / \mathrm{kg}(\mathrm{Gl})$ ou submetidos ao mesmo tratamento e tratados pelo butorfanol (GII) ou com doses menores de tiopental e tratados com butorfanol (GIII) em diferentes momentos. * indica diferença estatística entre grupos para cada momento; " indica diferença entre momentos para cada grupo $(p<0,05)$. 


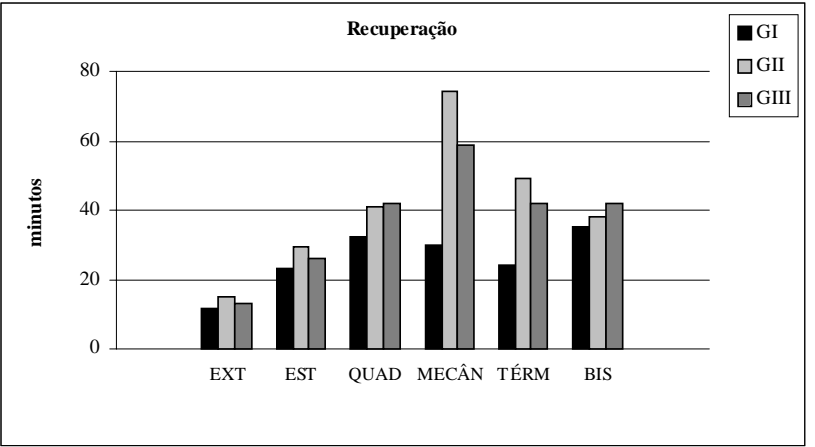

Figura 6 - Média dos valores da recuperação anestésica em minutos, referentes ao período de tempo de extubação orotraqueal (EXT), alcance da posição esternal (EST), posição quadrupedal (QUAD), algimetria mecânica (MECÂN), algimetria térmica (TERM) e valores derivados do Îndice Biespectral (BIS).

Letras minúsculas diferentes indicam diferenças significativas $(p<0,05)$ entre grupos para cada momento.

Tabela 3 - Valores medianos, $1^{\circ}$ e $3^{\circ}$ quartis das variáveis respiratórias, em cães anestesiados pelo sevofluorano, pré-tratados com levomepromazina, induzidos com tiopental sódico na dose de $12,5 \mathrm{mg} / \mathrm{kg}$ (GI) ou submetidos ao mesmo tratamento e tratados pelo butorfanol (GII) ou com doses menores de tiopental e tratados com butorfanol (GIII) em diferentes momentos (M).

\begin{tabular}{|c|c|c|c|c|c|c|c|c|c|c|c|}
\hline \multirow{2}{*}{ Variávei } & Momentos & MO & $\overline{\text { M1 }}$ & M2 & M3 & M4 & M5 & M6 & M7 & M8 & M9 \\
\hline & GI & $22,0^{A(2)}$ & $15,0^{B}$ & $12,0^{C}$ & $10,0^{C}$ & $11,0^{c}$ & $11,0^{c}$ & $13,0^{C}$ & $11,0^{C}$ & $13,0^{c}$ & $17,0^{B}$ \\
\hline \multirow{5}{*}{$\begin{array}{c}f \\
(\mathrm{mpm})\end{array}$} & $1^{\circ}-3^{\circ}$ quartis & $17-29$ & $13-27$ & $9-18$ & $9-13$ & $8-12$ & $9-15$ & $10-14$ & $10-15$ & $9-14$ & $15-27$ \\
\hline & 'Gil' & $21,0^{(4,2)}$ & 13,0 & 9,0 & 9,0 & 8,0 & 7,0 & 8,0 & 9,0 & 10,0 & 18,0 \\
\hline & $1^{\circ}-3^{\circ}$ quartis & $13-30$ & $12-18$ & $5-11$ & $5-13$ & $7-12$ & $7-16$ & $7-15$ & $7-15$ & $7-13$ & $13-26$ \\
\hline & "Gill' & 20,0 A'(2)"' & $14,0^{\mathrm{B}-}$ & $8,0^{8+}$ & 9,0 & 8,0 & 8,0 & 9,0 & "10,0 & "10,0 & $14,0^{\prime}$ \\
\hline & $1^{\circ}-3^{\circ}$ quartis & $16-23$ & $11-20$ & $7-12$ & $7-10$ & $6-10$ & $6-9$ & $6-10$ & $8-11$ & $8-13$ & $12-16$ \\
\hline \multirow{6}{*}{$\begin{array}{c}\mathrm{V}_{\mathrm{T}} \\
(\mathrm{ml})\end{array}$} & GI & $179,5^{(1,2)}$ & 219,0 & 181,5 & 168,0 & 193,5 & 191,5 & 205,5 & 233,0 & 234,0 & 191,0 \\
\hline & $1^{\circ}-3^{\circ}$ quartis & $128-250$ & $194-363$ & $138-203$ & $124-205$ & $170-209$ & $155-227$ & $178-231$ & $208-255$ & $193-264$ & $129-265$ \\
\hline & Gili' & $226,5^{(1,2)}$ & 230,5 & 228,5 & 245,0 & 230,0 & 211,5 & 215,5 & 211,5 & 226,5 & 193,0 \\
\hline & $1^{\circ}-3^{\circ}$ quartis & $216-293$ & $177-255$ & $151-320$ & 107312 & $136-345$ & $172-337$ & $189-365$ & $197-394$ & $185-383$ & $168-287$ \\
\hline & "'"'Gilil'"' & $317,0^{(1+2,2)}$ & 208,5 & 248,0 & 212,0 & 223,5 & 227,5 & 261,5 & 249,5 & 252,5 & 209,0 \\
\hline & $1^{\circ}-3^{\circ}$ quartis & $216-356$ & $152-297$ & $182-273$ & $164-233$ & $191-243$ & $188-248$ & $213-327$ & $181-261$ & $191-335$ & $189-262$ \\
\hline \multirow{7}{*}{$\begin{array}{c}\mathrm{V}_{\mathrm{M}} \\
(\mathrm{I} / \mathrm{min})\end{array}$} & GI & $4,9^{A(2)}$ & $2,7^{C}$ & $2,1^{v}$ & $1,3^{\mathrm{E}}$ & $1,6^{E}$ & $1,9^{5}$ & $2,2^{\square}$ & $2,1^{D}$ & $2,3^{D}$ & $4,1^{B}$ \\
\hline & $1^{\circ}-3^{\circ}$ quartis & $2,8-6,5$ & $1,8-3,1$ & $1,5-2,5$ & $1,2-2,1$ & $1,3-2,2$ & $1,4-2,7$ & $1,8-2,7$ & $1,8-2,8$ & $1,9-2,8$ & $2,1-4,6$ \\
\hline & Gii & $4,5^{A(2)}$ & $1,7^{\mathrm{CV}^{-}}$ & $1,5^{E}$ & $1,4^{\mathrm{E}}$ & $1,7^{E^{\cdots}}$ & $1,7^{\mathrm{E}}$ & $1,8^{E}$ & $2,0^{C}$ & $2,0^{c}$ & $2,5^{B}$ \\
\hline & $1^{\circ}-3^{\circ}$ quartis & $2,7-8,1$ & $1,5-3,6$ & $1,4-1,9$ & $1,3-2,0$ & $1,6-2,7$ & $1,2-2,0$ & $1,5-2,1$ & $1,7-2,3$ & $1,6-2,3$ & $2,1-3,5$ \\
\hline & Gilil' & $3,3^{(1,2), 2)}$ & 2,5 & 1,9 & 1,6 & 1,5 & 1,4 & 1,7 & 1,8 & 1,9 & 2,9 \\
\hline & $1^{\circ}-3^{\circ}$ quartis & $2,1-4,1$ & $1,9-3,9$ & $1,8-2,2$ & $1,2-1,8$ & $1,2-2,0$ & $1,3-2,0$ & $1,4-2,3$ & $1,5-2,3$ & $1,5-2,5$ & $1,8-3,2$ \\
\hline & GI & $35,5^{\mathrm{D}}$ & $36,5^{\mathrm{D}}$ & $39,0^{\mathrm{Cb}}$ & $45,0^{A}$ & $45,5^{A}$ & $44,0^{A}$ & $43,5^{\mathrm{B}}$ & $43,0^{C}$ & $42,0^{C}$ & $32,0^{E}$ \\
\hline \multirow{5}{*}{$\begin{array}{l}\mathrm{ETCO}_{2} \\
(\mathrm{mmHg})\end{array}$} & $1^{\circ}-3^{\circ}$ quartis & $35-37$ & $33-37$ & $39-41$ & $41-49$ & $44-48$ & $41-48$ & $39-46$ & $39-46$ & $38-44$ & $30-34$ \\
\hline & GII & $36,0^{-C^{\prime}}$ & $38,5^{c}$ & $46,0^{A a}$ & $47,5^{\mathrm{A}}$ & $47,5^{\mathrm{A}}$ & $47,0^{\mathrm{A}}$ & $45,0^{A}$ & $45,0^{\mathrm{A}}$ & $44,0^{\mathrm{B}}$ & $33,5^{5}$ \\
\hline & $1^{\circ}-3^{\circ}$ quartis & $33-40$ & $35-39$ & $45-51$ & $45-49$ & $43-48$ & $44-50$ & $43-52$ & $41-51$ & $37-47$ & $32-35$ \\
\hline & GIII & $35,5^{\mathrm{B}}$ & $35,5^{\mathrm{B}}$ & $45,0^{\text {Aa }}$ & $45,5^{\mathrm{A}}$ & $45,0^{\mathrm{A}}$ & $48,0^{A}$ & $46,0^{\mathrm{A}}$ & $45,5^{A}$ & $45,5^{A}$ & $34,0^{\mathrm{B}}$ \\
\hline & $1^{\circ}-3^{\circ}$ quartis & $33-37$ & $29-37$ & $41-47$ & $43-50$ & $43-53$ & $45-50$ & $41-51$ & $40-52$ & $39-53$ & $31-37$ \\
\hline
\end{tabular}

Letras maiúsculas diferentes indicam diferenças significativas $(p<0,05)$ entre momentos para cada grupo.

Letras minúsculas diferentes indicam diferenças significativas $(p<0,05)$ entre grupos para cada momento.

(1) Não houve diferença estatisticamente significativa na comparação dos momentos dentro do grupo.

(2) Não foram verificadas diferenças significativas $(p>0,05)$ entre grupos para cada momento. 
Tabela 4 - Valores medianos, $1^{\circ}$ e $3^{\circ}$ quartis das variáveis gases inalados, em cães anestesiados pelo sevofluorano, prétratados com levomepromazina, induzidos com tiopental sódico na dose de $12,5 \mathrm{mg} / \mathrm{kg}$ (Gl) ou submetidos ao mesmo tratamento e tratados pelo butorfanol (GII) ou com doses menores de tiopental e tratados com butorfanol (GIII) em diferentes momentos (M).

\begin{tabular}{|c|c|c|c|c|c|c|c|c|c|c|c|}
\hline & Momentos & M0 & M1 & M2 & $\begin{array}{l}\mathbf{M 3} \\
\end{array}$ & M4 & M5 & M6 & M7 & M8 & M9 \\
\hline \multirow{6}{*}{$\begin{array}{c}\mathrm{FeO}_{2} \\
(\mathrm{mmHg})\end{array}$} & & & & & & & & & & & \\
\hline & GI & $14,0^{\mathrm{Dc}}$ & $14,5^{\mathrm{D}}$ & $87,5^{\mathrm{B}}$ & $90,5^{\mathrm{Aa}}$ & $91,0^{\mathrm{Aa}}$ & $91,0^{\text {Аа }}$ & $91,0^{\mathrm{A}}$ & $91,0^{A}$ & $91,0^{\mathrm{A}}$ & $17,0^{\mathrm{Ca}}$ \\
\hline & $1^{\mathrm{O}}-3^{\mathrm{O}}$ quartis & $14-16$ & $14-15$ & $85-89$ & $90-92$ & $90-92$ & $90-92$ & $90-92$ & $90-92$ & $91-93$ & $17-37$ \\
\hline & GII" & $16,0^{\mathrm{Ea}}$ & $14,0^{\mathrm{F}}$ & $78,0^{5-1}$ & $84,0^{\mathrm{Cb}}$ & $88,0^{\mathrm{Cb}}$ & $88,0^{8 \mathrm{Bb}}$ & $89,0^{\mathrm{A}}$ & $90,0^{\mathrm{A}}$ & "90,5 & $16,5^{\text {Eäb" }}$ \\
\hline & $1^{\mathrm{O}}-3^{\mathrm{O}}$ quartis & $15-16$ & $14-15$ & $62-83$ & $83-89$ & $87-90$ & $88-90$ & $88-91$ & $89-91$ & $86-91$ & $16-17$ \\
\hline & $1^{\mathrm{O}}-3^{\mathrm{O}}$ quartis & $14-15$ & $14-16$ & $64-84$ & $84-88$ & $88-90$ & $88-90$ & $88-91$ & $89-91$ & $86-91$ & $16-17$ \\
\hline \multirow{4}{*}{$\begin{array}{c}\mathrm{FiO}_{2} \\
(\mathrm{mmHg})\end{array}$} & $\overline{\text { GI }}$ & $21,0^{\mathrm{Cc}}$ & $21,0^{\mathrm{C}}$ & $92,5^{\mathrm{Ba}}$ & $96,0^{\text {Aa }}$ & $97,0^{\text {Aa }}$ & $96,5^{\text {Aa }}$ & $96,5^{\mathrm{A}}$ & $96,5^{\mathrm{A}}$ & $96,0^{A}$ & $20,0^{\mathrm{C}}$ \\
\hline & $1^{\mathrm{O}}-3^{\mathrm{O}}$ quartis & $20-21$ & $21-21$ & $91-94$ & $96-97$ & $97-97$ & $96-98$ & $96-99$ & $96-97$ & $95-99$ & $20-67$ \\
\hline & GIII & $20,5^{\mathrm{Da}}$ & $21,0^{\mathrm{D}}$ & $88,5^{\mathrm{Ca}}$ & $93,0^{\mathrm{Bb}}$ & $95,5^{\mathrm{Ab}}$ & $95,0^{\mathrm{Ab}}$ & $95,0^{\mathrm{A}}$ & $96,5^{\mathrm{A}}$ & $96,5^{\mathrm{A}}$ & $20,0^{\mathrm{Bb}}$ \\
\hline & $1^{\mathrm{O}}-3^{\mathrm{O}}$ quartis & $20-21$ & $21-21$ & $78-91$ & $91-95$ & $94-96$ & $94-96$ & $94-97$ & $94-97$ & $95-97$ & $20-20$ \\
\hline \multirow{5}{*}{$\begin{array}{c}\mathrm{Fe}_{\text {SEVO }} \\
(\%)\end{array}$} & $\overline{\text { GI }}$ & & & $2,0^{(1)}$ & $2,3^{\mathrm{a}}$ & $2,3^{\mathrm{a}}$ & 2,1 & $\overline{1,9}$ & $1,9^{\mathrm{a}}$ & $1,9^{\mathrm{a}}$ & \\
\hline & $1^{\mathrm{O}}-3^{\mathrm{O}}$ quartis & & & $1,7-2,3$ & $2,1-2,8$ & $2,0-2,7$ & $1,9-2,2$ & $1,6-2,2$ & $1,6-2,2$ & $1,4-2,2$ & \\
\hline & GII & & & $1,4^{(1)}$ & $1,4^{6}$ & $1,6^{6}$ & 1,7 & 1,6 & $1,4^{6 \cdots}$ & $1,3^{6}$ & \\
\hline & $1^{\mathrm{O}}-3^{\mathrm{O}}$ quartis & & & $0,62-2,2$ & $0,71-2,0$ & $1,1-1,9$ & $1,3-2,1$ & $1,3-1,9$ & $1,3-1,6$ & $1,2-1,6$ & \\
\hline & GIII & & & $1,4^{(1)}$ & $1,7^{6}$ & $1,7^{6}$ & 1,8 & 1,9 & $1,7^{\mathrm{a}}$ & $1,6^{\mathrm{a}}$ & \\
\hline \multirow{3}{*}{$\begin{array}{c}\mathrm{Fi}_{\text {SEVO }} \\
(\%)\end{array}$} & $1^{\mathrm{O}}-3^{\mathrm{O}}$ quartis & & & $0,85-2,9$ & $1,0-2,4$ & $1,4-2,4$ & $1,4-2,4$ & $1,4-2,2$ & $1,3-1,9$ & $1,3-1,8$ & \\
\hline & GIII & & & $2,0^{(1,2)}$ & 1,8 & 1,9 & 2,0 & 1,8 & '"'l, & 1,5 & \\
\hline & $1^{\mathrm{O}}-3^{\mathrm{O}}$ quartis & & & $1,6-2,5$ & $1,9-2,8$ & $1,8-2,6$ & $1,8-2,6$ & $1,6-2,5$ & $1,7-2,5$ & $1,6-2,0$ & \\
\hline
\end{tabular}

Letras maiúsculas diferentes indicam diferenças significativas $(p<0,05)$ entre momentos para cada grupo.

Letras minúsculas diferentes indicam diferenças significativas $(p<0,05)$ entre grupos para cada momento.

(1) Não houve diferença estatisticamente significativa na comparação dos momentos dentro do grupo.

(2) Não foram verificadas diferenças significativas $(p>0,05)$ entre grupos para cada momento.

= não foram feitas avaliações nestes momentos. 
Tabela 5 - Valores medianos, $1^{\circ}$ e $3^{\circ}$ quartis das variáveis hemogasométricas, em cães anestesiados pelo sevofluorano, prétratados com levomepromazina, induzidos com tiopental sódico na dose de $12,5 \mathrm{mg} / \mathrm{kg}$ (Gl) ou submetidos ao mesmo tratamento e tratados pelo butorfanol (GII) ou com doses menores de tiopental e tratados com butorfanol (GIII) em diferentes momentos (M).

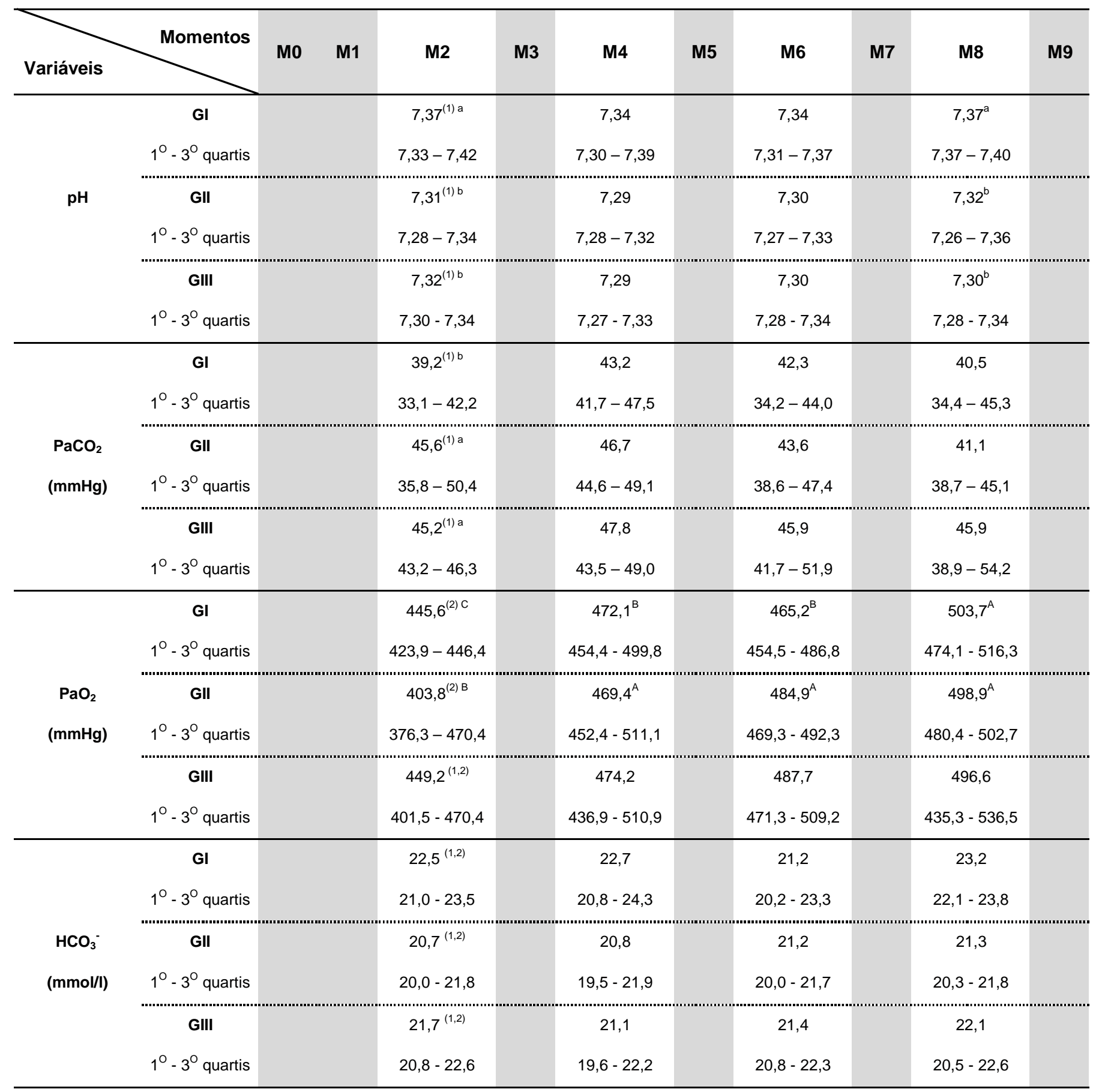

Letras maiúsculas diferentes indicam diferenças significativas $(p<0,05)$ entre momentos para cada grupo.

Letras minúsculas diferentes indicam diferenças significativas $(p<0,05)$ entre grupos para cada momento.

(1) Não houve diferença estatisticamente significativa na comparação dos momentos dentro do grupo.

(2) Não foram verificadas diferenças significativas $(p>0,05)$ entre grupos para cada momento.

$=$ não foram feitas avaliações nestes momentos. 


\section{Discussão}

A utilização da levomepromazina na MPA e tiopental sódico na indução anestésica reflete uma das técnicas mais utilizadas na rotina anestesiológica em pequenos animais. Entretanto, ainda se buscam diversas associações para se conseguir uma anestesia geral balanceada e satisfatória. A utilização de opióides tem sido bastante empregada como coadjuvante da anestesia inalatória, para se minimizarem os efeitos indesejáveis de uma depressão nas funções cardiovascular e respiratória, redução do anestésico geral empregado, proporcionando, além disso, analgesia ao paciente durante a anestesia e no pós-operatório.

A administração do tiopental sódico pela via intravenosa na dose referida por Massone (2003) de 12,5 mg/kg promoveu indução suave e rápida, sendo que somente 0 animal 02 de Gll apresentou apnéia durante 15 minutos, sendo assistido através da ventilação mecânica e posteriormente recuperando a ventilação espontânea.

A dose média requerida de tiopental para indução anestésica nos animais de Glll foi de 7,05 mg/kg confirmando o resultado esperado de potencialização deste fármaco através da associação do butorfanol e levomepromazina na MPA. A intubação nesses animais foi realizada com sucesso e não foi necessária dose suplementar de tiopental. A redução da temperatura retal observada ao longo dos momentos pode ser atribuída à utilização da levomepromazina, do tiopental e ao próprio agente volátil (sevofluorano) que possuem ação depressora sobre os centros termorreguladores do hipotálamo, causando ainda vasodilatação periférica, redução da produção de calor pela diminuição do metabolismo basal, concomitantemente com a perda de calor pelas vias respiratórias (Fantoni e Cortopassi, 2002; Massone, 2003).

A FC não apresentou variações significativas nos animais que não sofreram o tratamento com o butorfanol, onde a $\mathrm{Fe}_{\mathrm{SEV}}$ permaneceu entre 1,9 e 2,3\%, mantendo valores ligeiramente superiores ao valor basal, porém dentro dos valores fisiológicos para a espécie, encontrando suporte nos achados de Mutoh et al. (1997) e Oliva et al. (2000). Por outro lado, deve-se considerar a taquicardia observada após a indução neste mesmo grupo que é resultante da utilização do tiopental sódico na indução anestésica, que acarreta elevação da resistência vascular periférica e bloqueio vagal (Fantoni e Cortopassi, 2002; Massone, 2003).

A administração do butorfanol nas doses clínicas usuais está associada à redução da FC (Trim, 1983). A mesma autora relatou redução de $26 \%$ da FC na dose de $0,4 \mathrm{mg} / \mathrm{kg}$ IV. Nos animais tratados com o butorfanol pode-se notar redução um pouco mais acentuada após a administração da MPA quando comparados aos animais de GI. Este resultado pode ser devido à associação do butorfanol a levomepromazina na MPA, indo ao encontro dos achados de Cornick e Hartsfield (1992) que observaram redução da FC após administração deste opióide associado a acepromazina.

Apesar da estabilidade da FC durante a manutenção anestésica pelo sevofluorano nos animais de Gll e Glll, os valores desse parâmetro se mantiveram abaixo dos valores observados em GI, que não receberam o butorfanol na MPA. A partir daí podemos ressaltar a influência do butorfanol sobre a FC, confirmando os achados de Trim (1983). Greene et al.
(1990) encontraram uma FC significativamente abaixo do valor basal durante 30 minutos de anestesia pelo halotano, enquanto que, em outro estudo em cães anestesiados pelo isofluorano, a FC não sofreu grandes alterações no decorrer da manutenção (Tyner, 1989).

Chamou a atenção, a ausência da taquicardia, normalmente ocasionada após a administração do tiopental, naqueles animais que receberam o butorfanol associado à levomepromazina. Este fenômeno provavelmente se deve a bradicardia causada pelos opióides por estímulo vagal central (Fantoni e Cortopassi, 2002).

A hipotensão notada durante a manutenção anestésica pelo sevofluorano em cães é semelhante à que ocorre no homem, sendo esta redução proporcional à concentração de anestésico administrada (Kazama e Ikeda,1985). Deve-se atentar, no entanto, que neste experimento foi utilizado o tiopental sódico na indução anestésica e butorfanol na MPA. Logo após a administração do tiopental houve redução da PAM, provavelmente por sua ação depressora do centro vasomotor (Massone, 2003). Os animais tratados pelo butorfanol apresentaram valores inferiores de pressão arterial sangüínea, em relação aos demais, nos últimos 30 minutos de anestesia pelo sevofluorano, podendo este resultado ser atribuído à ação central deste opióide, que atua reduzindo a resistência vascular periférica, a qual pode ser elevada concomitantemente com reduções na FC e débito cardíaco (Muldoon et al., 1983). Estes mesmos autores, isolando anéis de veia safena de cães, observaram que o butorfanol deprimia a resposta de contratilidade por eletroestimulação, além de reduzir a liberação de norepinefrina. Sendo assim, tanto os efeitos diretos como os indiretos sobre a musculatura lisa vascular podem contribuir para a redução da pressão arterial sistêmica após a administração do butorfanol (Muldoon et al., 1983; Tyner et al., 1989).

A medida direta da pressão arterial apresenta algumas vantagens sobre os métodos indiretos. Os valores obtidos da primeira são mais fidedignos em todas as pressões mensuradas, inclusive em pacientes hipotensos (Sawer et al., 1991; Fantoni e Cortopassi, 2002). Entretanto, apesar dessas vantagens, a avaliação da pressão arterial pelo método indireto (não invasivo) tem sido freqüente, pois com o avanço tecnológico já podemos encontrar equipamentos que permitem a obtenção de valores mais confiáveis. Dentre as desvantagens do método indireto, encontrou-se a falta de precisão na avaliação da PAD, especialmente em pacientes hipotensos (Fantoni e Cortopassi, 2002). A correlação obtida entre os dois métodos foi altamente positiva, confirmando os achados de Sawer et al. (1991), nos permitindo assegurar que o método indireto é seguro em pacientes normotensos, além de permitir a avaliação das pressões com o animal consciente.

Um dos efeitos indesejáveis do opióide agonista puro é produzir depressão respiratória e, conseqüentemente, hipóxia (Fantoni e Cortopassi, 2002). O butorfanol é um agente opióide de ação agonista-antagonista (Vandam, 1981), cujo "efeito teto" é uma de suas propriedades vantajosas que confere menor depressão respiratória, ou seja, mesmo em doses elevadas, não acarreta maior depressão nesse sistema (Schurig et al., 1978; Murphy e Hug, 1981). 
Apesar dos animais de Gll revelarem uma capnometria discretamente mais elevada em M3, M4 e M5, neste grupo a dose utilizada do agente indutor foi de $12,5 \mathrm{mg} / \mathrm{kg} \mathrm{IV}$, podendo este resultado ter sido influenciado pelos efeitos do tiopental sobre o sistema respiratório. Entretanto, no geral, os achados relativos aos valores do $f, \mathrm{~V}_{\mathrm{T}}, \mathrm{V}_{\mathrm{M}}$ e ETCO2, em ambos os grupos durante anestesia pelo sevofluorano, sugerem a não interferência do butorfanol nessas variáveis, pois seguiram um mesmo padrão de resposta nos três grupos estudados. Assim também foi observado que, tanto a $\mathrm{FiO}_{2}$ como a $\mathrm{FeO}_{2}$, mantiveram-se dentro de um limite adequado, permitindo uma ventilação satisfatória e, conseqüentemente, troca gasosa adequada. Podemos sugerir que a depressão respiratória ocorrida é, ao menos em parte, devida ao efeito do tiopental sódico que além de deprimir a $f$ e o $\mathrm{V}_{\mathrm{T}}$, modifica as respostas compensatórias às alterações da $\mathrm{PaCO}_{2}$ e a hipóxia (Fantoni e Cortopassi, 2002). Não obstante, a evidência do efeito depressor do sevofluorano torna-se evidente, visto que logo após a interrupção da anestesia inalatória, os valores do $\mathrm{ETCO}_{2}$ reduziam-se significativamente, confirmando a ausência de depressão pós-anestésica, estando de acordo com estudos prévios observados por Oliva et al. (2000).

Não foram observadas diferenças importantes para as variáveis hemogasométricas, sendo esses valores mantidos dentro dos limites normais para a espécie canina, sugerindo que os tratamentos empregados não causaram alterações dignas de nota para tais atributos. A utilização do butorfanol como coadjuvante da anestesia inalatória com isofluorano (Tyner et al., 1989) e halotano (Greene, et al., 1990), também não resultaram em alterações hemogasométricas importantes.

Os valores médios da $\mathrm{Fe}_{\mathrm{SEV}}$ encontrados foram respectivamente de 2,05\% (GI); 1,48\% (GII) e 1,68\% (GIII) durante a anestesia, sugerindo redução da concentração do sevofluorano com a utilização do butorfanol na MPA. Não foram encontrados na literatura consultada, trabalhos referentes à utilização do butorfanol com o objetivo de reduzir o consumo do sevofluorano. Entretanto, resultados semelhantes foram obtidos por outros autores que, utilizando o butorfanol com outros agentes halogenados observaram redução da CAM do enfluorano em $11 \%$ e $15 \%$ quando se administrava butorfanol nas doses de $0,1 \mathrm{mg} / \mathrm{kg}$ e $0,3 \mathrm{mg} / \mathrm{kg}$, respectivamente (Murphy e Hug, 1982); e redução de $20 \%$ da CAM do isofluorano com o emprego do butorfanol na dose de $0,4 \mathrm{mg} /$ kg - IV em cães (Ko Jeff et al., 2000).

Quanto ao BIS, os menores níveis foram obtidos nos animais de GI, durante a anestesia pelo sevofluorano. Embora haja poucos trabalhos no cão em relação ao BIS, tal comportamento se assemelha ao homem, que constatados por outros pesquisadores, demonstraram que a utilização de opióides, como componente da anestesia geral, não responde pelo componente hipnótico, ou seja, são observadas alterações mínimas no BIS quando se utilizam diversos tipos de opióides (Glass et al., 1997; Viana, 2001).

Fato interessante foi observado ao se realizar os métodos nociceptivos de termo e pressoalgimetria, pois ao serem ava- liados estes estímulos, em momento algum se notou qualquer alteração na concentração tanto inspiratória como expiratória do sevofluorano, demonstrando que não havia resposta do paciente ao estímulo nociceptivo.

O sevofluorano, por possuir baixa solubilidade sangüínea, contribuiu para uma recuperação rápida da anestesia (Smith et al., 1996). Sendo assim, o butorfanol não influenciou no período de extubação endotraqueal, bem como no período de posição esternal e quadrupedal, visto que todos os animais apresentaram o mesmo padrão de recuperação anestésica, livre de complicações. A recuperação da consciência avaliada pelo BIS também levou o mesmo período de tempo desde a interrupção da volatilização do sevofluorano, visto que o BIS aproximava-se de 100 indicando que todos os animais estavam em alerta.

A utilização do butorfanol como analgésico preemptivo é bastante promissora devido à sua menor depressão sobre o sistema respiratório, bem como o seu "efeito teto". Em cães anestesiados pelo isofluorano e que receberam butorfanol (0,2 $\mathrm{mg} / \mathrm{kg}$ IM), a duração da ausência de resposta após o pinçamento da cauda foi de 1,5 $\pm 1,5$ hora (Grimm et al., 2000). Em ovelhas, o butorfanol mostrou-se bastante eficaz no que tange a avaliação algimétrica pelo método térmico, promovendo analgesia de 120 a 130 minutos na dose de $0,2 \mathrm{mg} / \mathrm{kg}$ (Waterman et al., 1991). Rosa (2001), utilizando o butorfanol em cães, em associação a levomepromazina/midazolam/ quetamina, observou um período de analgesia de três horas em média, através da avaliação algimétrica pelos métodos térmico e mecânico, o mesmo utilizado nesta pesquisa.

\section{Conclusões}

Em face dos resultados obtidos, pode-se concluir que:

- a associação do butorfanol à levomepromazina proporcionou estabilidade hemodinâmica, respiratória e hemogasométrica nos grupos estudados, não ocorrendo nenhuma complicação trans ou pós-anestésica. Além disso, amenizou a taquicardia causada pelo tiopental, reduzindo sua dose de indução, com sinergismo por potenciação em 43,68\%.

- a analgesia causada pelo butorfanol provavelmente reduziu o consumo do sevofluorano durante a manutenção anestésica, que foi constatada pela redução da $\mathrm{Fe}_{\mathrm{SEV}} \mathrm{em}$ média de 27,8\% em Gll e 18,05\% em GIII.

- o índice bispectral (BIS) constituiu-se em dado útil da hipnose, que foi mais acentuada em Gl e menos acentuada em GIl e GIII, demonstrando que o butorfanol melhorou a qualidade anestésica, reduzindo a quantidade de tiopental e sevofluorano, diminuindo conseqüentemente o componente hipnótico da anestesia.

- a avaliação algimétrica pelos métodos mecânico e térmico comprovou que o butorfanol prolonga a analgesia pósanestésica, não interferindo no período de recuperação, pois todos os animais apresentaram o mesmo tempo correspondente.

\section{Agradecimentos}

Agradece-se à FAPESP pela concessão da Bolsa de Doutorado e Auxílio à Pesquisa sem os quais não seria viável a execução desta Pesquisa. 


\section{Referências}

CORNICK, J. L.; HARTSFIELD, S.M. Cardiopulmonary and behavioral effects of combinations of acepromazine/butorphanol and acepromazine/oxymorphone in dogs. J. Am. Vet. Med. Assoc., v. 200 p. 1952-1656, 1992.

GLASS, P. S.; BLOOM, M.; KEARSE, L.; ROSOW, C.; SEBEL, P.; MANBERG, P. Bispectral analysis measures sedation and memory effects of Propofol, midazolam, isoflurane and alfentanil in healthy volunteers. Anesthesiology, v. 86, p. 836-347, 1997.

GREENE, S. A.; HARTSFIELD, S. M.;TYNER, C. L. Cardiovascular effects of butorphanol in halothane anesthetized dogs. Am. J. Vet. Res., v. 51, p. 1276-1279, 1990.

GRIMM, K. A.; TRANQUILLI, W. J.; THURMON, J. C.; BENSON, G. J. Duration of nonresponse to noxious stimulation after intramuscular administration of buthorphanol, medetomidine, or a buthorphanolmedetomidine combination during isoflurane administration in dogs. Am. J. Vet. Res., v. 61, p. 42-47, 2000.

FANTONI, D. T.; CORTOPASSI, S. R. G. Anestesia em cães e gatos. São Paulo: Editora Roca, 2002.

KAZAMA, T.; IKEDA, K. The comparative cardiovascular effects and induction time of sevoflurane with isoflurane and halothane in dogs. Anesthesiology, v. 63, p. A17, 1985.

KO JEFF, C. H.; LANGE, D. N.; MANDSAGER, R. E.; PAYTON, M. E.; BOWEN, C.; KAMATA, A.; KUO, W-C. Effects of buthorphanol and carprofen and the minimum alveolar concentration of isofluorane in dogs. J. Am. Vet. Méd. Assoc., v. 217, p. 1025-1028, 2000.

MASSONE, F. Anestesiologia veterinária farmacologia e técnicas. 4 ed. Rio de Janeiro: Guanabara Koogan, 2003.

MULDOON, S.; OTTO, J.; FREAS,W.; WATSON, R. L. The effects of morphine, nalbuphine, and butorphanol on adrenergic function in canine saphenous veins. Anesth. Analg., v. 62, p. 21-28,1983.

MURPHY, M. R.; HUG, C.C. "Ceilling effect" of butorphanol (Stadol) as an anaesthetic supplement. Anesthesiology, v. 55, p. 260, 1981.

The enflurane sparing effect of morphine, butorphanol, and nalbuphine. Anesthesiology, v. 57, p. 489-492, 1982.

MUTOH, T.; NISHIMURA, R.; KIM, H.; MATSUNAGA, S.; SASAKI, N. Cardiopulmonary effects of sevoflurane, compared with halothane, enflurane, and isoflurane, in dogs. Am. J. Vet. Res., v. 58, p. 885-890, 1997.

MUTOH, T.; NISHIMURA, R.; SASAKI, N. Effects of medetomidinemidazolam, midazolam- butorphanol or acepromazine-butorphanol as premedicants for mask induction of anesthesia with sevoflurane in dogs. Am. J. Vet. Res., v. 63, p. 1022-1028, 2002.
NOLAN, A., LIVINGSTON, A., MORRIS, R., WATERMAN, A.E. Techniques for the comparison of thermal and mechanical nociceptivo stimuli $n$ the sheep. J. Pharm. Meth., v. 17, p. 39-49, 1987.

OLIVA, V. N. L. S.; MASSONE, F.; CURI, P. R.; NETO F. J. T. Avaliação cardiocirculatória do sevofluorano como agente de manutenção anestésica em cães, em diferentes concentrações de oxigênio e óxido nitroso. Arq. Bras. Med. Vet. Zootec., v. 52, n. 4, p. 130-137, 2000. OTERO, P.;BONAFINE, R.; GUERRERO, J.; PORTELA, D.; HALLU, R. Clinical evaluation of butorphanol in dogs: its use as analgesic during preanaesthetic medication. Selecciones Veterinarias,v.8, n. 3, p. 331335, 2000.

ROSA, A. L. Avaliação algimétrica por estímulo nociceptivo térmico e pressórico em cães pré-tratados com levomepromazina, midazolam e quetamina associados ou não ao butorfanol ou buprenorfina. 2001. 141f. Tese (Doutorado) - Faculdade de Medicina de Botucatu, Universidade Estadual Paulista. Botucatu.

ROSOW, C.; MANBERG, P.J. Bispectral Index Monitoring. Anesth. Clin. North Am., v. 2, p. 89-107, 1998.

SAWYER, D. C.;BROWN, M.;STRILER, E. L.;DURHAM, R. A.;LANGHAM, M. A.; RECH, R .H. Comparision of direct and indirect blood pressure measurement in anesthetized dogs. Lab. Anim. Sci., v. 41, n. 2, p. 134 138, 1991

SCHURIG, J. E., CAVANAGH, R. L., BUYNISKI. Effect of butorphanol and morphine on pul monary mechanics, arterial blood pressure and venous plasma histamine in the anesthetized dog. Arch. Int. Pharmacodyn. Ther., v. 233, p. 296-304, 1978.

SMITH, I.; NATHANSON, M.; WHITE, P.F. Sevoflurane-a long-waited volatile anaesthtic. Br. J. Anaesth., v. 76, p. 435-445, 1996.

TRIM, C.M. Cardiopulmonary effects of butorfanol tartrate in dogs. Am. J. Vet. Res., v. 44, p. 329-331, 1983.

TYNER, C. L.; GREENE, S. A.; HARTSFIELD, S. M. Cardiovascular effects of butorphanol administration in isoflurane- $\mathrm{O}_{2}$ anesthetized dogs. Am. J. Vet. Res., v. 50, p. 1340-1342, 1989.

VANDAM, L. D. Butorphanol. N. Engl. J. Med., v. 302, p. 381-384, 1981. VERNON, J. M.; LANG, E.; SEBEL, P. S.; MANBERG, P. Prediction of moviment using bispectral electroencephalographic analysis during propofol/alfentanil or isoflurane/alfentanil anesthesia. Anesth. Analg., v. 80, p. 780-785,1995.

VIANNA, P. T. G., Monitor de profundidade da hipnose. A eletroencefalografia bispectral. Rev. Bras. Anestesiol., v. 1, n. 4, p. 7 14, out.nov.dez., 2001.

WATERMAN, A. E.; AMIN, A. Analgesic activity and respiratory effects of butorphanol in sheep. Res. in Vet. Sci., v. 51, p. 19-23, 1991. 